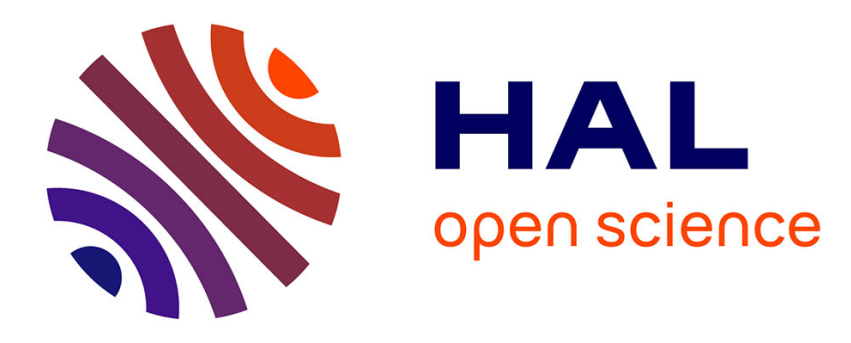

\title{
Design and Control of the Induction Motor Propulsion of an Electric Vehicle
}

Bekheira Tabbache, Abdelaziz Kheloui, Mohamed Benbouzid

\section{To cite this version:}

Bekheira Tabbache, Abdelaziz Kheloui, Mohamed Benbouzid. Design and Control of the Induction Motor Propulsion of an Electric Vehicle. IEEE VPPC 2010, Sep 2010, Lille, France. pp.1-6. hal00578426

\section{HAL Id: hal-00578426 \\ https://hal.science/hal-00578426}

Submitted on 20 Mar 2011

HAL is a multi-disciplinary open access archive for the deposit and dissemination of scientific research documents, whether they are published or not. The documents may come from teaching and research institutions in France or abroad, or from public or private research centers.
L'archive ouverte pluridisciplinaire HAL, est destinée au dépôt et à la diffusion de documents scientifiques de niveau recherche, publiés ou non, émanant des établissements d'enseignement et de recherche français ou étrangers, des laboratoires publics ou privés. 


\title{
Design and Control of the Induction Motor Propulsion of an Electric Vehicle
}

\author{
B. Tabbache ${ }^{1,2}$, A. Kheloui ${ }^{2}$ and M.E.H. Benbouzid ${ }^{1}$ \\ ${ }^{1}$ University of Brest, EA 4325 LBMS \\ Rue de Kergoat, CS 93837, 29238 Brest Cedex 03, France \\ ${ }^{2}$ Electrical Engineering Department, Polytechnic Military Academy, 16111 Algiers, Algeria \\ E-mail: Mohamed.Benbouzid@univ-brest.fr
}

\begin{abstract}
This paper deals with a methodology for presizing the induction motor propulsion of an Electric Vehicle (EV). Based on the $\mathrm{EV}$ desired performances, the induction motor optimal power can be calculated. The final objective is to find its minimum weight, volume, and cost that meet the design constraints with minimum power under the European urban (ECE-15) and sub-urban (EUDC) driving cycles. The power presizing methodology is validated through extensive simulations for different induction motor-based EVs using a siding mode control technique.
\end{abstract}

Index Terms-Electric Vehicle (EV), induction motor, presizing, driving cycle.

\section{INTRODUCTION}

Recently, Electric Vehicles (EVs) including fuel-cell and hybrid vehicles have been developed very rapidly as a solution to energy and environmental problems. From the point of view of control engineering, EVs have much attractive potential [1].

The shortcomings, which caused the EV to lose its early competitive edge, have not yet been totally overcome. Indeed, EVs have a low energy density and long charging time for the present batteries. Therefore, optimal energy management is very important in EVs; in addition optimum design of the electric motor, selection of a proper drive, and optimal control strategy are the other major factors in EVs.

Selection of traction motors for the EV propulsion systems is a very important step that requires special attention. In fact, the automotive industry is still seeking for the most appropriate electric propulsion system. In this case, key features are efficiency, reliability and cost. The process of selecting the appropriate electric propulsion systems is however difficult and should be carried out at the system level. In fact, the choice of electric propulsion systems for EVs mainly depends on three factors: driver expectation, vehicle constraint, and energy source. For EVs propulsion, the cage induction motor seems to be candidate that better fulfils their major requirements. This is mainly due to its low cost, robustness, highly reliable and free from maintenance [2].

This paper presents a methodology for presizing the induction motor propulsion of an EV. Based on the EV desired performances, the induction motor optimal power can be calculated. The main objective behind is to find its minimum weight, volume, and cost that meet the design constraints with minimum power under the European urban (ECE-15) and suburban (EUDC) driving cycles.

\section{EV MODELING}

\section{A. Nomenclature}

$V \quad=$ vehicle speed;

$\alpha \quad=$ Grade angle;

$P_{v} \quad=$ Vehicle driving power;

$F_{w} \quad=$ Road load;

$F_{r o}=$ Rolling resistance force;

$F_{s f}=$ Stokes or viscous friction force;

$F_{a d}=$ Aerodynamic drag force;

$F_{c r}=$ Climbing and downgrade resistance force;

$\mu=$ Tire rolling resistance coefficient $(0.015<\mu<0.3)$;

$m \quad=$ Vehicle mass;

$g=$ Gravitational acceleration constant;

$k_{A}=$ Stokes coefficient;

$\xi \quad=$ Air density;

$C_{w}=$ Aerodynamic drag coefficient $\left(0.2<C_{w}<0.4\right)$;

$A_{f} \quad=$ Vehicle frontal area;

$v_{0}=$ is the head-wind velocity;

$F \quad=$ Tractive force;

$k_{m}=$ Rotational inertia coefficient $\left(1.08<k_{m}<1.1\right)$;

$a=$ Vehicle acceleration;

$J \quad=$ Total inertia (rotor and load);

$\omega_{m} \quad=$ Motor mechanical speed;

$T_{B}=$ Load torque accounting for friction and windage;

$T_{L} \quad=$ Load torque;

$T_{m}=$ Motor torque;

$i=$ Transmission ratio;

$\eta_{t} \quad=$ Transmission efficiency;

$R=$ Wheel radius;

$J_{V}\left(J_{W}\right)=$ Shaft (wheel) inertia moment;

$\lambda=$ Wheel slip.

\section{B. Dynamics Analysis}

This section derives the driving power to ensure vehicle operation (Fig. 1) [3].

1) Road load and tractive force. The road load consists of

$F_{w}=F_{r o}+F_{s f}+F_{a d}+F_{c r}$

The rolling resistance force $F_{r o}$ is produced by the tire flattening at the roadway contact surface.

$F_{r o}=\mu m g \cos \alpha$ 


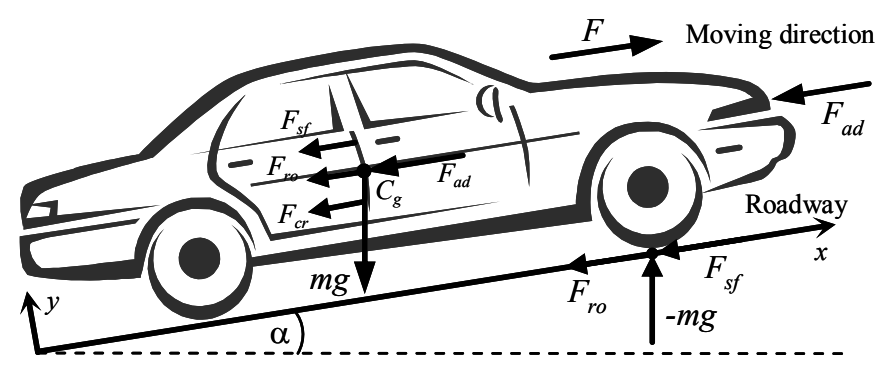

Fig. 1. Elementary forces acting on a vehicle.

The rolling resistance force can be minimized by keeping the tires as much inflated as possible.

$$
F_{s f}=k_{A} V
$$

Aerodynamic drag, $F_{a d}$, is the viscous resistance of air acting upon the vehicle.

$$
F_{a d}=\frac{1}{2} \xi C_{w} A_{f}\left(V+V_{0}\right)^{2}
$$

The climbing resistance ( $F_{c r}$ with positive operational sign) and the downgrade force $\left(F_{c r}\right.$ with negative operational sign) is given by

$F_{c r}= \pm m g \sin \alpha$

The tractive force in an electric vehicle is supplied by the electric motor in overcoming the road load. The equation of motion is given by

$k_{m} m \frac{d V}{d t}=F-F_{w}$

The net force $\left(F-F_{w}\right)$, accelerates the vehicle (or decelerates when $F_{w}$ exceeds $F$ ).

2) Motor ratings and transmission. The power required to drive a vehicle has to compensate the road load $F_{w}$.

$P_{v}=V F_{w}$

The mechanical equation (in the motor referential) used to describe each wheel drive is expressed by

$J \frac{d \omega_{m}}{d t}+T_{B}+T_{L}=T_{m}$

The following equation is derived due to the use of a reduction gear.

$\omega_{\text {Wheel }}=\frac{\omega_{m}}{i}$ and $T_{\text {Wheel }}=T_{m} i \eta_{t}$

The load torque in the motor referential is given by.

$T_{L}=\frac{T_{L \text { Wheel }}}{i}=\frac{R}{i} F_{\omega}$
The vehicle global inertia moment in the motor referential is given by

$$
\left\{\begin{array}{l}
J=J_{W}+J_{V} \\
J_{V}=\frac{1}{2} m \frac{R^{2}}{i^{2}}(1-\lambda)
\end{array}\right.
$$

\section{EV TRACTION MOTOR AND GEAR RATIO DESIGN}

\section{A. Traction Motor Characteristics}

For EVs propulsion, the cage induction motor seems to be candidate that better fulfils the major above-mentioned features [2]. Figure 2 shows the induction motor drive characteristics that should be dealt with when used as the EV propulsion [4-5].

\section{B. Tractive Force and Transmission Requirement}

The induction motor developed force on the EV driven wheels is expressed by

$F=\eta_{t} \frac{T_{m} N_{m}}{R}$

where $N_{m}$ is the induction motor speed.

The transmission gear ratio $i$ is designed such that the EV reaches its maximum speed at the maximum induction motor speed.

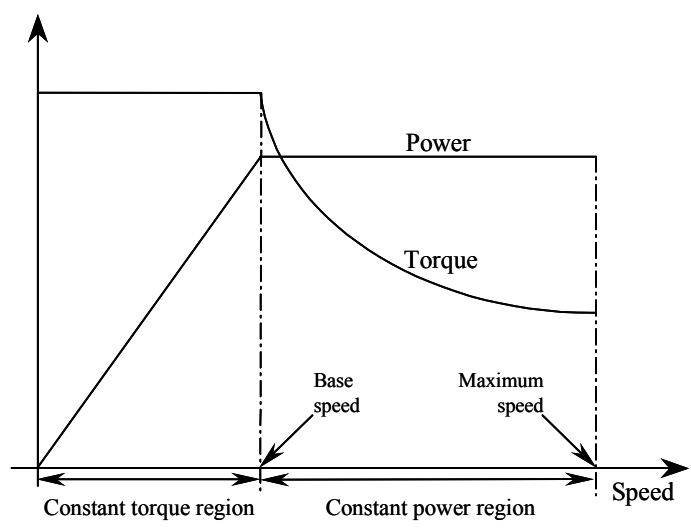

(a) Electric traction

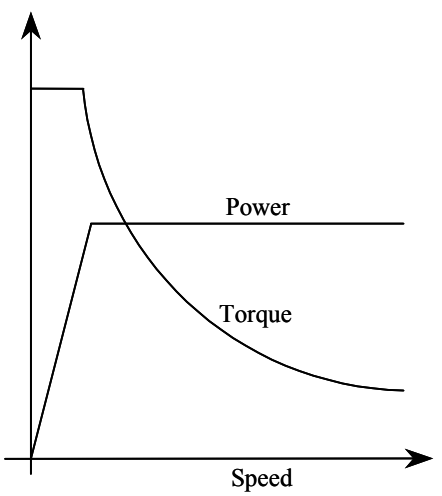

(b) Tractive effort versus speed.

Fig. 2. EV typical characteristics. 
$i=\frac{\pi N_{m_{-} \max } R}{30 V_{\max }}$

A high value of this ratio has the advantage of allowing the use of high-speed motors which have a better power density, but with the disadvantage of more volume and then higher cost. A good compromise is generally not to exceed a value of $i=10$. Moreover, if the induction motor has a wide constant power region, a single-gear transmission would be sufficient for a high-tractive force at low speeds.

\section{THE INDUCTION MOTOR PRESIZING}

Basic vehicle performance includes maximum cruising speed, gradeability, and acceleration.

The induction motor power presizing $\left(P_{m}\right)$ is done for the following case/vehicle: Acceleration $0-50 \mathrm{~km} / \mathrm{h}$ in $10 \mathrm{sec}$ on ground level; vehicle mass $1500 \mathrm{~kg}$; rolling resistance coefficient 0.015 ; aerodynamic drag coefficient 0.3 ; front area $0.8 \mathrm{~m}^{2}$; maximum speed $120 \mathrm{~km} / \mathrm{h}$; maximum speed of the induction motor $3500 \mathrm{rpm}$; wheel radius $0.318 \mathrm{~m}$ (175/80R14); transmission efficiency (single-gear + differential) $90 \%$; and zero head-wind velocity.

In this first presizing stage, the EV operation consists of three main segments: initial acceleration, cruising at the vehicle speed maximum and cruising at maximum gradeability.

\section{A. Initial Acceleration}

In the case of initial acceleration, the induction motor presizing is based on two steps: The first one is done under simplifying assumptions (null aerodynamic force). The second one takes into account all EV resistance forces. The solution of (6) uses the base speed $\left(V_{b}\right)$ and the power found in the first step. The boundary conditions of (6) are: at $t=0, V$ $=0$ and at $t=t_{f}, V=V_{c r}$, where $V_{c r}$ is the cruising speed.

Using (6), the EV acceleration time is defined by

$t_{a}=\int_{0}^{V_{f}} \frac{k_{1}}{F-\left(k_{2} V^{2}+k_{3}\right)} d V$

where $V_{f}$ is the final speed; $k_{1}, k_{2}$ et $k_{3}$ are constants values: $k_{1}$ $=k_{m} \mathrm{~m} ; k_{2}=0.5 \xi C_{w} A_{f} ; k_{3}=m g\left(\sin \alpha+f_{r} \cos \alpha\right)$. This expression can reformulated as

$\frac{t_{a}}{\tau_{b}}=\frac{k_{b}^{2}}{\alpha_{b}-k_{b}}+\alpha_{b} \log \left[\frac{\alpha_{b}-k_{b}}{\alpha_{b}-1}\right]+k_{b}-1$

with $\alpha_{b}=\frac{P_{b}}{k_{3} m g V_{c r}}, k_{b}=\frac{V_{b}}{V_{c r}}, \tau_{b}=\frac{k_{m} V_{c r}}{k_{3} g}: P_{b}$ is the base power.

The analytical solution of (15) is shown by Fig. 3. It illustrates the necessary power-speed profile for the EV initial acceleration in order to obtain the induction motor optimal power and base speed.

Figure 4 shows that below $V_{b}=0.4 V_{c r}$ it is not interesting to decrease $V_{b}$ because the necessary power does not greatly decrease.

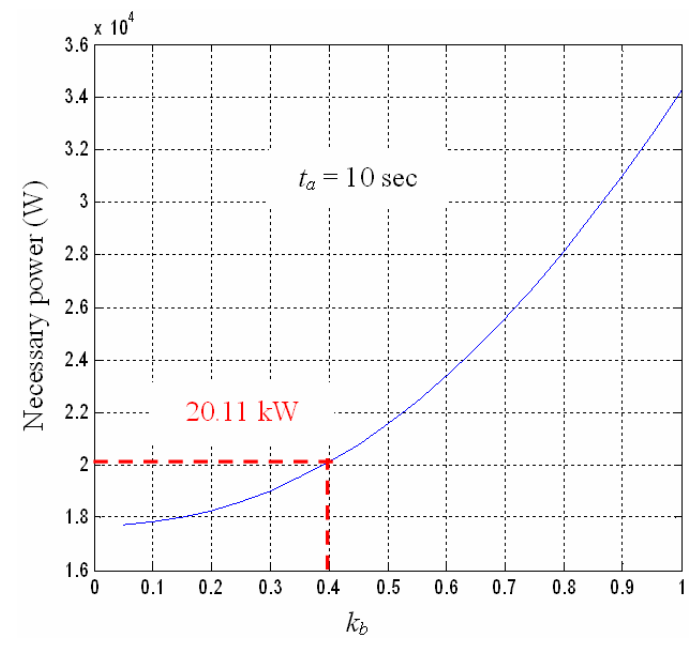

Fig. 3. Necessary power: Acceleration from 0 to $50 \mathrm{~km} / \mathrm{h}$ in $10 \mathrm{sec}$ on ground level.

On the other hand, the acceleration force tends to considerably increase. This will lead to increased propulsion motor size (the torque is an important dimensioning parameter in terms of size and weight). In this case, the first EV base parameters are the base speed $\left(V_{b}=0.4 V_{c r}=20\right.$ $\mathrm{km} / \mathrm{h})$ and the base power $\left(P_{b}=20.11 \mathrm{~kW}\right)$.

Using these base values, the presizing second step consist in finding (6) numerical solution including all the resistance forces. In this case, the obtained initial acceleration time is larger than that specified in the desired performance. The correction of the base power and speed values are done using an iterative procedure combining analytical numerical solutions. The new value is then: $P_{b}=21.06 \mathrm{~kW}$, as illustrated by Fig. 4 .

\section{B. Cruising at Maximum Vehicle Speed on Ground Level}

To validate the base power and speed choices, it is mandatory to evaluate the induction motor power and torque in different operation mode and in particular at maximum vehicle speed $\left(V_{\max }\right)$.

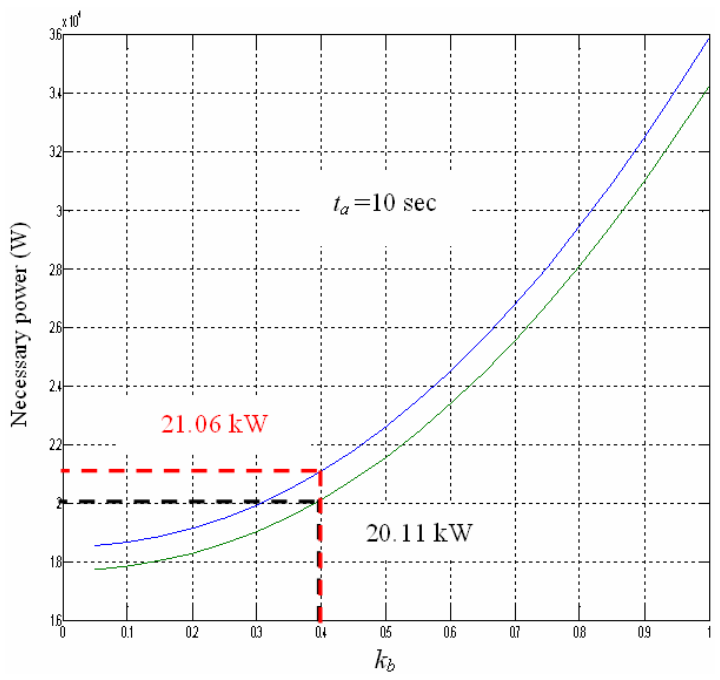

Fig. 4. Induction motor power: Step 1 (green) and step 2 (blue). 
The power requirement to cruise at the EV maximum speed can be obtained by:

$$
P_{V_{\max }}=\frac{1}{2} \xi C_{w} A_{f} V_{\max }^{2}+m g\left(\cos \alpha+f_{r} \sin \alpha\right) V_{\max }
$$

The necessary power at different speed in ground level is illustrated by Fig. 5. The result is obtained under a specified gear ratio value and the motor maximum speed. The base power found in the previous section is then replaced by the new obtained one. The new base speed is obtained by the same previous iterative procedure (Fig. 5).

The carried out computations illustrate that the needed power motor at $120 \mathrm{~km} / \mathrm{h}$ is about $22.92 \mathrm{~kW}$, in which transmission losses are taken into account.

\section{Gradeability Checking}

The power found in the previous section is able to propel the EV at a regular highway speed $(120 \mathrm{~km} / \mathrm{h})$ on a flat road. Using the induction motor torque and speed profiles, the necessary power on a $15 \%$ and $10 \%$ graded road can be evaluated.

Figure 6 indicates that the motor above calculated power of $22.92 \mathrm{~kW}$ can propel the EV at $33.54 \mathrm{~km} / \mathrm{h}$ and $46.44 \mathrm{~km} / \mathrm{h}$ on a $15 \%$ and $10 \%$ graded road, respectively.

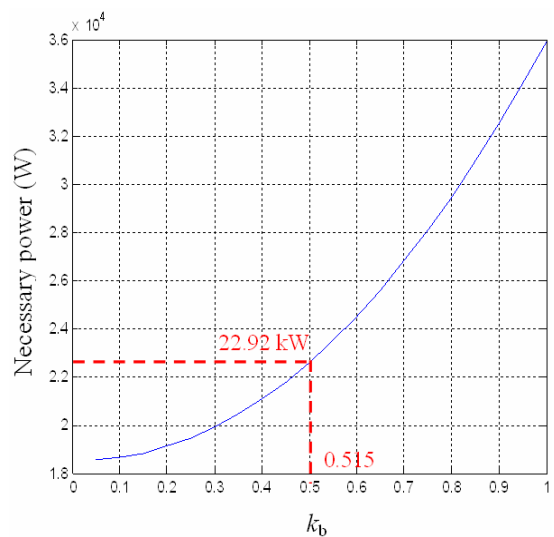

Fig. 5. The induction motor necessary power for EV maximum speed

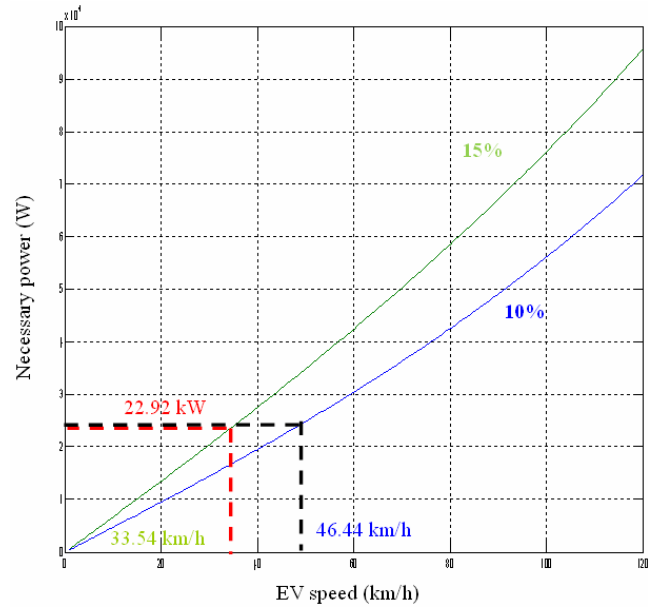

Fig. 6. The induction motor necessary power for gradeability.

\section{The Necessary Power Using Driving Cycles}

Another consideration in the induction motor power presizing is the average power when driving with some typical stop-and-go driving patterns.

The average power can be obtained by

$$
P_{\text {average }}=\frac{1}{T} \int_{0}^{T}\left(m g f_{r}+\frac{1}{2} \xi C_{w} A_{f} V^{2}\right) V d t+\frac{1}{T} \int_{0}^{T} k_{m} m \frac{d V}{d t} d t
$$

It is difficult to describe the road load and vehicle speed variations in all actual traffic environments accurately and quantitatively. However, some representative driving cycles have been developed to emulate typical traffic environments. Among them, the European Elementary urban cycle (ECE), the sub-urban cycle (EUDC) and sub-urban cycle for lowpowered vehicles (EUDCL) (Fig. 7) [5].

Figure 8 shows then the EV induction motor necessary power in the case of the European driving cycle with and without regenerative braking. Compared to the needed power shown in Fig. 8, the optimal power found in the previous section is greater and can therefore meet the power requirement in these driving cycles.

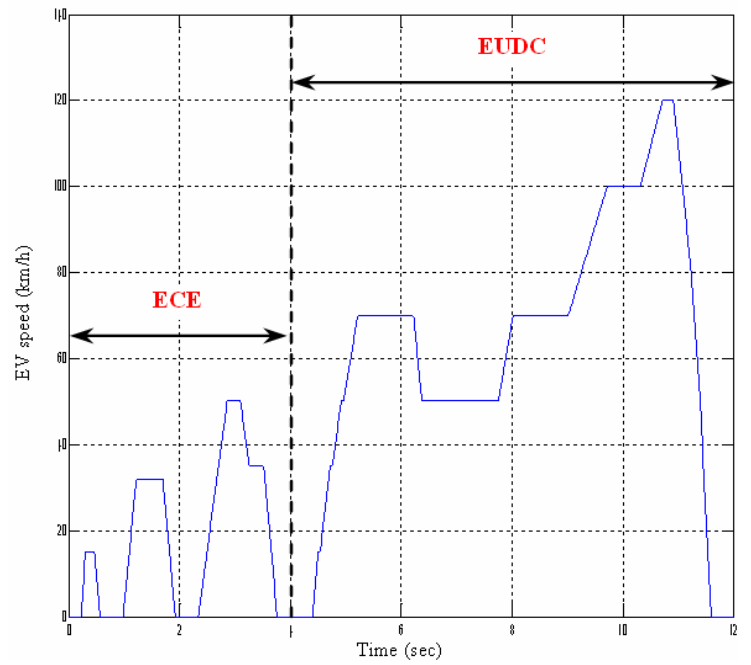

Fig. 7. The European ECE + EUDC driving cycle.

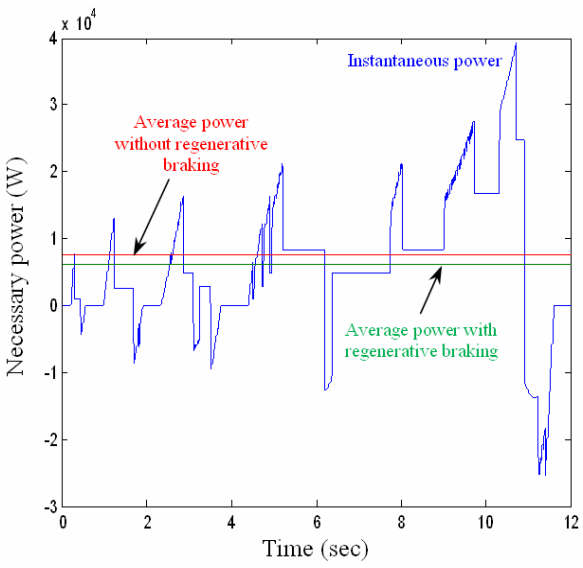

Fig. 8. The induction motor necessary power for the ECE + EUDC driving cycle. 


\section{EV CONTROL TESTS USING A PRESIZED INDUCTION MOTOR}

The aim of this section is to check the induction motorbased EV performance under road load, especially the climbing resistance, and then choose the induction motor necessary power to propel the EV in normal driving cycles. For that purpose a sliding mode approach has been adopted to carry-out control tests on three induction motors for different graded road [6].

The acceleration and the corresponding time are defined by the European driving cycle (Fig. 7). Figure 9 shows then the $\mathrm{EV}$ acceleration in this driving cycle.

Simulations are carried-out on different induction motors with different power ratings. These simulations use the EV parameters given in section IV. The main objective here is to find the minimum motor weight, volume and cost that will meet the design constraints with minimum power under the European ECE and EUDC driving cycles. After the average power calculation, the control use standard motors: $15 \mathrm{~kW}, 37$ $\mathrm{kW}$ and $75 \mathrm{~kW}$. In this case the control is implemented in the extended constant power range.

The maximum gradeability of each motor is obtained by an iterative procedure using the EV model as indicated by Fig. 10. This Figure also shows necessary instantaneous and average powers to propel the EV.

For the validation of the obtained maximum gradeability, Fig. 11 illustrates the sliding mode control performances of the $37 \mathrm{~kW}$ induction motor-based EV including the $15.6 \%$ graded road. As clearly shown by the EV dynamics (Fig. 11.a), the developed torque variations are as large as are the variations of the accelerator pedal and the road profile. Moreover, very speed tracking performances are achieved. This was also the case of the 15 and $75 \mathrm{~kW}$ induction motorbased EV: The obtained results clearly validate the proposed design methodology.

\section{CONCLUSIONS}

A methodology for presizing the induction motor propulsion of an EV was presented. Based on the EV desired performances, the induction motor optimal power can be evaluated.

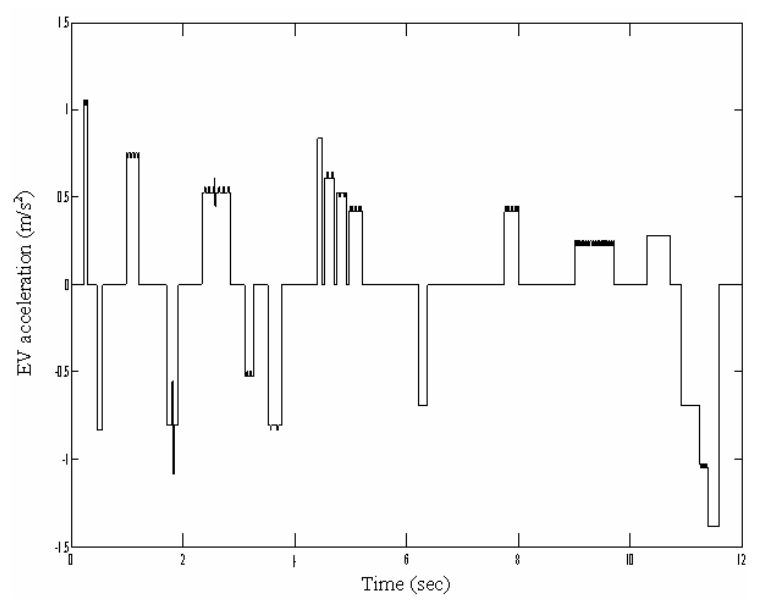

Fig. 9. EV acceleration in normal driving cycle (ECE + EUDC).

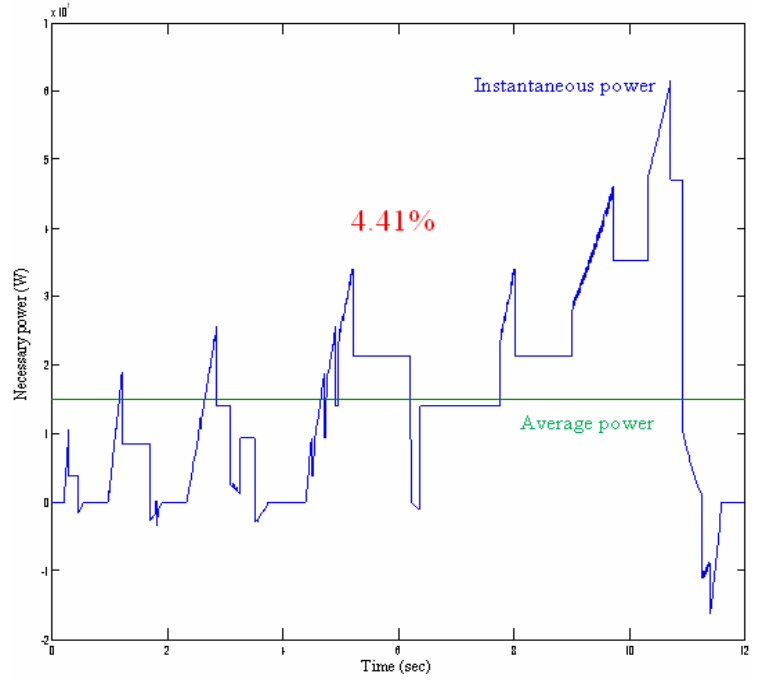

(a) $15 \mathrm{~kW}$ induction motor.

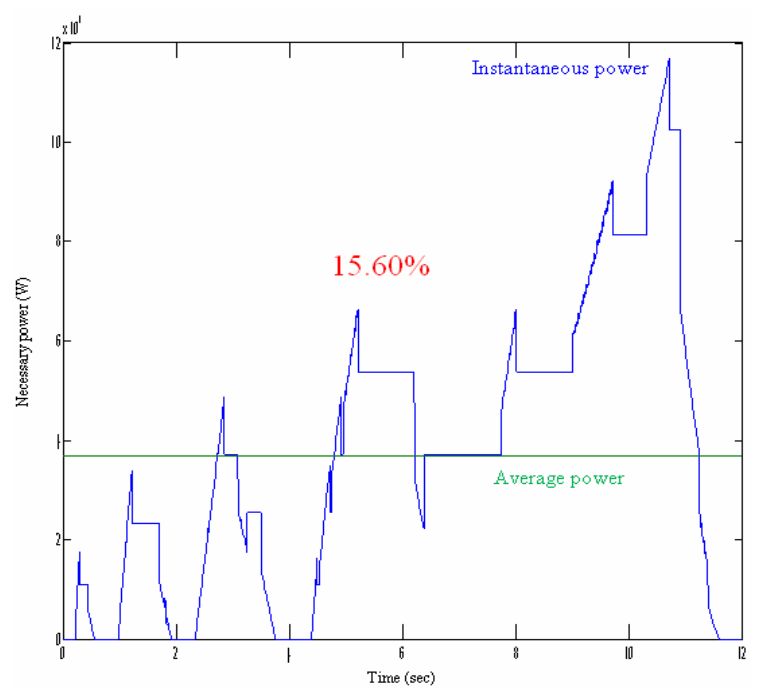

(b) $37 \mathrm{~kW}$ induction motor.

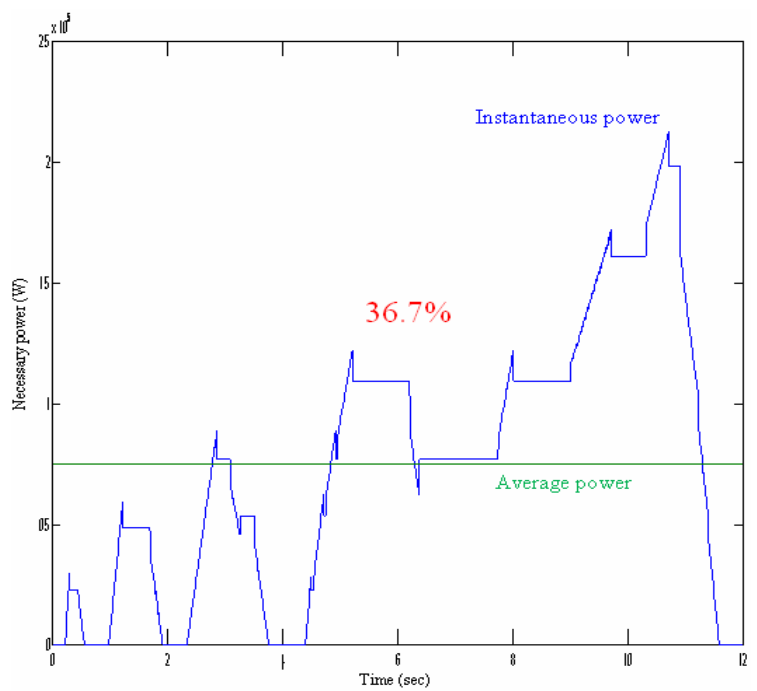

(c) $75 \mathrm{~kW}$ induction motor.

Fig. 10. Maximum gradeability and necessary instantaneous and average powers. 


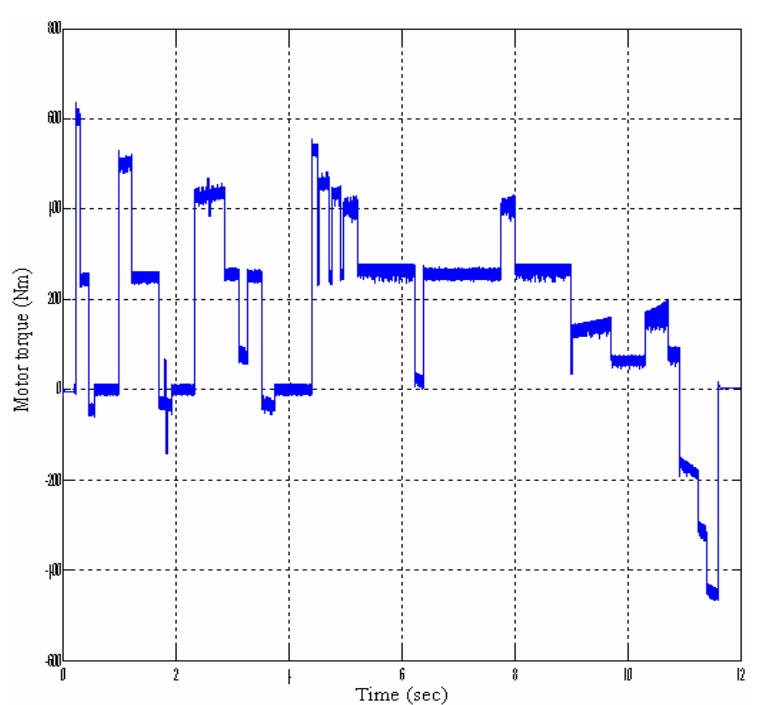

(a) the induction motor torque.

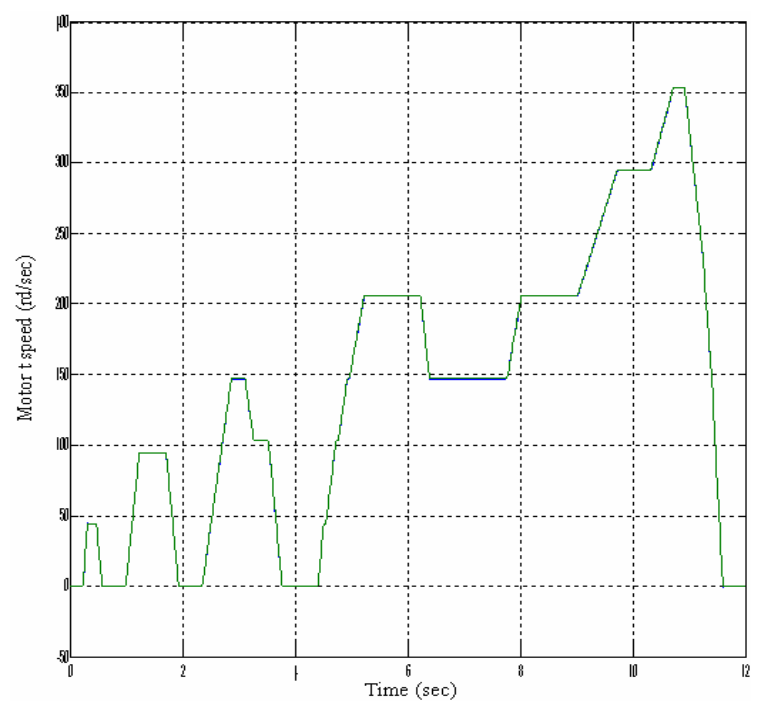

(b) Reference and the induction motor speed.

Fig. 11. The $37 \mathrm{~kW}$ induction motor-based EV control performances.

The main objective behind is to find its minimum weight, volume, and cost that meet the design constraints with minimum power under a desired driving cycle (the European one in our case).

The presizing methodology has been validated through extensive simulations for different induction motor-based EVs using a well-established advance control technique (the sliding mode).
APPENDIX

RATED DATA OF THE $15 \mathrm{KW}$ INDUCTION MOTOR

$15 \mathrm{~kW}, 1480 \mathrm{rpm}, p=2$

$R_{s}=0.2147 \Omega, R_{r}=0.2205 \Omega$

$L_{s}=0.065181 \mathrm{H}, L_{r}=0.065181 \mathrm{H}, M=0.0641 \mathrm{H}$

$J=0.102 \mathrm{kgm}^{2}, k_{f}=0.009541 \mathrm{Nms}$

RATED DATA OF THE 37 KW INDUCTION MOTOR

$37 \mathrm{~kW}, 1480 \mathrm{rpm}, p=2$

$R_{s}=0.0851 \Omega, R_{r}=0.0658 \Omega$

$L_{s}=0.0314 \mathrm{H}, L_{r}=0.0291 \mathrm{H}, M=00.0291 \mathrm{H}$,

$\mathrm{J}=0.37 \mathrm{~kg} . \mathrm{m}^{2}, k_{f}=0.02791 \mathrm{Nm} . \mathrm{s}$

RATED DATA OF THE 75 KW INDUCTION MOTOR

$37 \mathrm{~kW}, 1480 \mathrm{rpm}, p=2$

$R_{\mathrm{s}}=0.03552 \Omega, R_{r}=0.02092 \Omega$

$L_{s}=0.015435 \mathrm{H}, L_{r}=0.015435 \mathrm{H}, M=0.0151 \mathrm{H}$

$J=1.25 \mathrm{kgm}^{2}, k_{f}=0.03914 \mathrm{Nms}$

\section{REFERENCES}

[1] C.C. Chan, "The state of the art of electric and hybrid vehicles," Proceedings of the IEEE, vol. 90, n², pp. 247-275, February 2002.

[2] M. Zeraoulia, M.E.H. Benbouzid and D. Diallo, "Electric motor drive selection issues for HEV propulsion systems: A comparative study," IEEE Trans. Vehicular Technology, vol. 55, n6, pp. 1756-1764, November 2006.

[3] A. Haddoun , M.E.H. Benbouzid and D. Diallo, "A loss-minimization DTC scheme for EV induction motors," IEEE Trans. Vehicular Technology, vol. 56, ${ }^{\circ} 1$, pp. 81-88, January 2007.

[4] M. Ehsani, K.M. Rahman and H.A. Toliyat, "Propulsion system design of electric and hybrid vehicles," IEEE Trans. Industrial Electronics, vol. 44, n¹, pp. 19-27, February 1997.

[5] M. Ehsani, Y. Gao, S.E. Gay, A. Emadi, Modern Electric, Hybrid Electric, and Fuel Cell Vehicles: Fundamentals, Theory, and Design, CRC Press, 2004.

[6] M.E.H. Benbouzid, D. Diallo, and M. Zeraoulia, "Advanced faulttolerant control of induction-motor drives for $\mathrm{EV} / \mathrm{HEV}$ traction applications: From conventional to modern and intelligent control techniques," IEEE Trans. Vehicular Technology, vol. 56, n², pp. 519528, March 2007. 